\title{
Disturbance rejection using IMC Tuned PID controller with improved filter
}

\author{
B. Mabu Sarif ${ }^{1}$, D. V. Ashok Kumar ${ }^{2}$, M. Venu Gopala Rao ${ }^{3}$ \\ ${ }^{1}$ Department of Electrical and Electronics Engineering, Koneru Lakshmaiah Education Foundation, India \\ ${ }^{2}$ RGM College of Engineering and Technology, India \\ ${ }^{3}$ PVP Siddhartha Institute of Technology, India
}

\section{Article Info}

Article history:

Received Apr 4, 2020

Revised Jun 25, 2020

Accepted Jul 20, 2020

\section{Keywords:}

Disturbance rejection

FOPTD

IMC

Improved filter

Integral criteria

Robustness

Sensitivity

\begin{abstract}
IMC-PID controllers supply exceptional set point tracking but slow disturbance refutation, because of introduction of slow process pole introduced by the conventional filter. Disturbance rejection is important in many industrial applications over set point tracking. An enhanced IMC filter cascaded with PID controller with internal model control tuning system (IMC-PID) is presented right now for efficient disruption rejection and reliable first order process operation with time delay (FOPTD). The optional filter does away with the sluggish dominant pole. The present learning shows that the recommended IMC filter provide excellent trouble rejection irrespective of where the trouble enters the procedure and provide highquality robustness to duplicate deviation in surroundings of accepting in difference with other method cited in the text. Reenactment study was led to show the feasibility of the suggested approach on processes with different $\theta / \tau$ ratios by measuring the controller parameters while retaining the same robustness as regards maximal sensitivity. His efficiency of the closed loops was assessed utilizing integral error parameters. Viz. ISE, ITAE, IAE. The recommended filter provides excellent response pro lag dominant processes.
\end{abstract}

Copyright @ 2020 Institute of Advanced Engineering and Science. All rights reserved.

Corresponding Author:

B. Mabu Sarif,

Department of Electrical and Electronics Engineering,

Koneru Lakshmaiah Education Foundation,

Vaddeswaram, Guntur, Andhra Pradesh, India.

Email: gsn.bms786@gmail.com.

\section{INTRODUCTION}

The mainly extensively employ controller inside the procedure manufacturing be Proportional integral derivative (PID) controller, since it be able to guarantee acceptable performance by means of straightforward algorithm intended for a broad collection of process. It is significant toward letter that price advantage relation attain during the PID controller is hard toward attain through additional controllers [1-3]. It is establish that $97 \%$ of the contracted controllers utilize PID algorithm [4]. The Internal Model Control (IMC) provide a progressive, effectual, usual, general, sole, influential, and straightforward structure for psychiatry and mixture of control system presentation [5,6]. Since of the broadmindedness and enhanced presentation of the IMC found alteration regulation, the logically resulting IMC-PID alteration technique have involved the concentration of engineering users over the last decade. The renowned IMC-PID tuning regulation has the benefit that a obvious cooperation flanked by closed loop presentation and toughness to reproduction doubts, be attain through a simply single user-defined alteration stricture, which be frankly associated toward the closed-loop time constant [1, 5, 7, 8]. In the IMC-PID alteration technique and direct synthesis (DS), the PID controller restriction is obtained by multiply the controller which supplies the preferred closed loop reaction [7-13]. Rejection of load disruption is one of the most important issues 
about process control. IMC-PID controller supply a high-quality set-point pathway but the disorder reply is sluggish, particularly when $[6,9,12]$. For the majority solitary loop controllers, trouble refusal is more significant than set-point pathway; a controller devises so as to highlights the trouble refusal be a significant mean objective $[6,9,14]$. The objective can be achieved by scheming the manager for trouble refusal, somewhat than set-point pathway, where PID controller flow by means of a filter be optional inside the text [3, 6-8, 10, 14-16].

The effectiveness of the IMC-PID is pedestal on top of the arrangement of the IMC filter. In the literature the filter arrangement be chosen in the direction of build the IMC controller attainable as pleasing the presentation supplies. The effectiveness of IMC controller and the shut estimate of IMC controller to perfect controller decide the effectiveness of the ensuing PID controller. Consequently appropriate IMC filter arrangement have toward exist chosen not on top of the presentation of IMC controller but the presentation of ensuing PID controller.

The PID alteration system explain so far in the writing have used process/plant which are First order plus time delay (FOPTD) and second order plus time delay (SOPTD) [11, 17-20]. It is been practical that the superior order models approximated by FOPTD and/or SOPTD can also complete the control objectives in acceptable mode $[2,17,18]$. This has stimulated to use replica sort lessening system for extrapolative place model. The current work considers the design of appropriate control approach for disorder elimination by combining IMC-PID controller with model order decrease. This designed controller is able of hush-up the fighting irrespective of the arrangement at which the interruption go into the closed-loop scheme, able of treatment model mismatches and parameter reservations.

The objectives of the current employment are:

- Identify the transfer function model/ reduce the higher order model of the process to FOPTD model which will be used as predictive model for IMC structure, using techniques Viz. Sundaresan and Krishnaswamy (S-K) described in [2].

- To believe IMC-PID cascaded with filter arrangement toward optimizes the presentation of scheme intended for consignment disturbance refusal.

- Present healthiness investigation by integrate perturbations into the deposit (extrapolative) replica restriction and assess presentation of the closed loop system inside conditions of essential mistake criterion.

Nomenclature:

$\begin{array}{ll}G_{P}(s) & \text { Process } \\ G_{C}(s) & \text { Controller } \\ G_{M}(s) & \text { Predictive plant model } \\ Q(s) & \text { IMC controller } \\ G_{M-}(s) & \text { Invertible part } \\ G_{M+}(s) & \text { Non invertible part } \\ G_{f}(s) & \text { Filter } \\ \lambda & \text { Filter time constant } \\ G_{P I D}(s) & \text { PID feedback controller } \\ R(s) & \text { Set point input } \\ D(s) & \text { Disturbance input } \\ L(s) & \text { Load disturbance input } \\ K_{P} & \text { Relative gain } \\ T_{i} & \text { Essential time } \\ T_{d} & \text { Offshoot time } \\ t_{d} & \text { Process time delay } \\ \tau & \text { Process time constant } \\ K & \text { Process gain }\end{array}$

\section{DESIGN OF IMC-PID CONTROLLER}

Morari and Garcia proposed internal model control [7, 21], characterizing it as a system in which the flow mechanism is explicitly a necessary segment of the controller. The intend procedure of IMC involve factorizing the analytical lodge model $G_{M}(s)$ as invertible $G_{M_{-}}(s)$ and non-invertible $G_{M_{+}}(s)$ parts as shown 
in (1) by easy factorization or every one go by factorization $[5,7,8,10,16]$. The IMC (2) is the opposite of the invertible $G_{M-}(s)$ portion of the plant model $G_{M}(s)$.

$$
G_{M}(s)=G_{M-}(s) G_{M+}(s)
$$

The IMC controller is designed as;

$$
Q(s)=G_{M-}^{-1}(s) G_{f}(s)
$$

The feedback controller form of Figure 1 is taken by the IMC controller incorporating small changes to Figure 2, which can be articulated logically as far as $Q(s)$ and $G_{M}(s)$ as (3)

$$
G_{C}(s)=\frac{Q(s)}{1-Q(s) G_{M}(s)}
$$

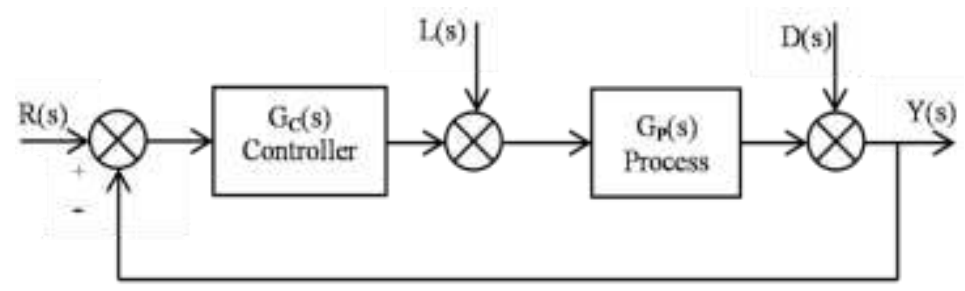

Figure 1. Feedback control structure

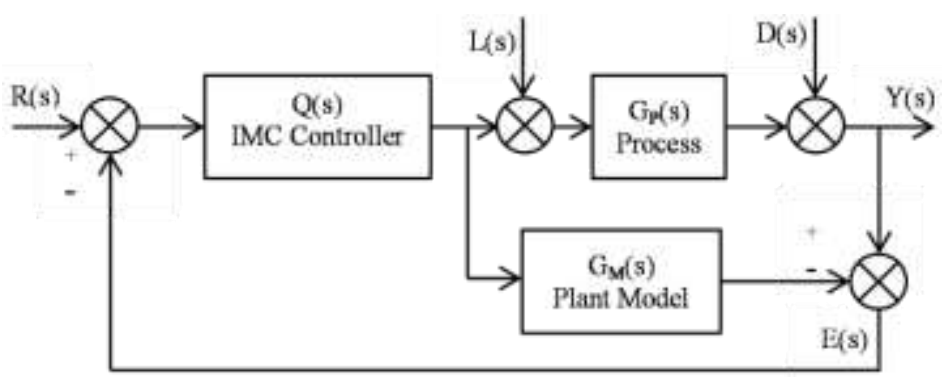

Figure 2. Essential IMC structure

The controller acquired in (3) does not have the typical form of PID, which can be obtained plummeting the controller form described in (4) or (5), with suitable approximations of process model dead time.

$$
\begin{aligned}
& G_{P I D}(s)=K_{P}\left(1+\frac{1}{T_{i} s}+T_{d} s\right) \\
& G_{P I D}(s)=K_{P}\left(1+\frac{1}{T_{i} s}+T_{d} s\right)\left(\frac{d s^{2}+c s+1}{a s^{2}+b s+1}\right)
\end{aligned}
$$

The production reply of the closed loop scheme for Set-point input, load trouble input and output load interruption input is (6),

$$
Y(s)=\frac{G_{C}(s) G_{P}(s)}{1+G_{C}(s) G_{P}(s)} R(s)+\frac{1}{1+G_{C}(s) G_{P}(s)} D(s)+\frac{G_{P}(s)}{1+G_{C}(s) G_{P}(s)} L(s)
$$




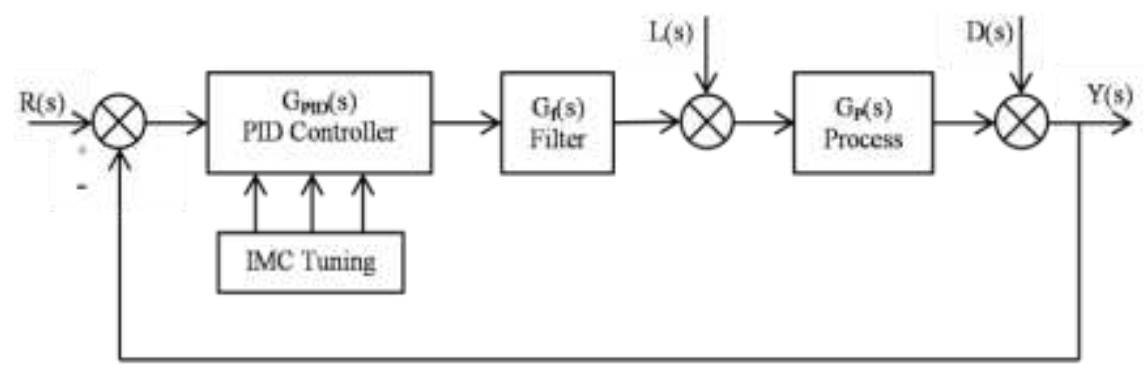

Figure 3. Proportional Integral Derivative Controller cascaded with

\section{IMC-PID TUNING RULES FOR FOPTD MODEL}

The most extensively utilized estimated model of the process is the FOPTD given by (7). The procedure for obtaining the FOPTD model is explained in [2]. The deposit replica $G_{M}(s)$ is factored keen on invertible and non-invertible segment using all pass factorization by similar to the holdup term $e^{-\theta_{s}}$ using first order Padé estimate.

$$
G_{M}(s)=\frac{K e^{-\theta s}}{\tau s+1}
$$

Padé Approximation of $e^{-\theta s}$ is $G_{M}(s)=\frac{K}{\tau s+1}\left(\frac{1-\frac{\theta}{2}}{1+\frac{\theta}{2}}\right)$

$$
\begin{aligned}
& G_{M}(s)=\frac{K}{\tau s+1}\left(\frac{1-\frac{\theta}{2}}{1+\frac{\theta}{2}}\right) \\
& G_{M}^{-}(s)=\frac{K}{\tau s+1}, G_{M}^{+}(s)=\frac{1-\frac{\theta}{2}}{1+\frac{\theta}{2}}
\end{aligned}
$$

The conservative IMC filter arrangement for step contribution is of the appearance of (10).

$$
G_{f}(s)=\frac{1}{(\lambda s+1)^{n}}
$$

The resultant IMC controller $Q(s)$ is

$$
Q(s)=\frac{1+\tau s}{K(\lambda s+1)}
$$

The perfect feedback controller, corresponding of IMC controller is

$$
G_{C}(s)=\frac{1}{K s}\left(\frac{\frac{\theta}{2} \tau s^{2}+\left(\frac{\theta}{2}+\tau\right) s+1}{\frac{\theta}{2} \lambda s+(\theta+\lambda)}\right)
$$

Rearranging (12), and comparing with (5), we get; 


$$
\begin{aligned}
& K_{P}=\frac{\frac{\theta}{2}+\tau}{K(\theta+\lambda)}, T_{i}=\frac{\theta}{2}+\tau, \quad T_{d}=\frac{\frac{\theta}{2} \tau}{\frac{\theta}{2}+\tau} \\
& b=c=d=0, a=\frac{\frac{\theta}{2} \lambda}{(\theta+\lambda)}
\end{aligned}
$$

The output response for FOPDT model of (6) for load disturbance with and of the form

$$
\frac{Y(s)}{D(s)}=\frac{K\left(\frac{\theta}{2} \lambda s^{2}+(\theta+\lambda) s\right)\left(1-\frac{\theta}{2} s\right)}{(1+\tau s)(1+\lambda s)\left(1+\frac{\theta}{2} s\right)^{2}}
$$

The relation between Output and the disturbance produces a process pole $s=-1 / x$. The effect of this, the response of the controller to disturbances becomes sluggish. To overcome this alternate filter of the form (16) is suggested.

Alternate form of filter is;

$$
G_{f}(s)=\frac{(\alpha s+1)^{n}}{(\lambda s+1)^{n+1}}
$$

Where $\mathrm{n}=0$ to 1 .

The controller of IMC $Q(s)$ is;

$$
Q(s)=\frac{(1+\tau s)}{K} \frac{(\alpha s+1)^{n}}{(\lambda s+1)^{n+1}}
$$

The perfect feedback controller, corresponding of IMC controller is;

$$
G_{C}(s)=\frac{\left(\frac{\theta}{2} \tau s^{2}+\left(\frac{\theta}{2}+\tau\right) s+1\right)(\alpha s+1)^{n}}{K\left[(\lambda s+1)^{n+1}\left(1+\frac{\theta}{2} s\right)-(\alpha s+1)^{n}\left(1-\frac{\theta}{2} s\right)\right]}
$$

The most favorable filter for FOPTD system is obtain with $n=1$

$$
G_{f}(s)=\frac{(\alpha s+1)^{1}}{(\lambda s+1)^{2}}
$$

The perfect feedback controller, corresponding of IMC controller for FOPTD is;

$$
G_{C}(s)=\frac{(\alpha s+1)}{K s(2 \lambda+0.5 \theta-\alpha)} \frac{\left(0.5 \theta \tau s^{2}+(0.5 \theta+\tau) s+1\right)}{\left[\frac{0.5 \theta \lambda^{2}}{(2 \lambda+0.5 \theta-\alpha)} s^{2}+\frac{\left(\lambda^{2}+\lambda \theta+0.5 \theta \alpha\right)}{(2 \lambda+0.5 \theta-\alpha)} s+1\right]}
$$

In (20) and (5), we obtain

$$
\begin{aligned}
& K_{P}=\frac{0.5 \theta+\tau}{K(2 \lambda+0.5 \theta-\alpha)}, T_{i}=\tau+0.5 \theta, T_{d}=\frac{0.5 \theta \tau}{0.5 \theta+\tau} \\
& a=\frac{\left(\lambda^{2}+\lambda \theta+0.5 \theta \alpha\right)}{(2 \lambda+0.5 \theta-\alpha)}, b=\frac{0.5 \theta \lambda^{2}}{(2 \lambda+0.5 \theta-\alpha)}, c=2 \alpha, d=\alpha^{2}
\end{aligned}
$$


The sluggish procedure pole $s=-1 / \tau$ is cancelled by the additional amount of autonomy provide by $\alpha$, it is obtained by computation of characteristic equation of the controller $\left[1-G_{M}(s) Q(s)\right]_{s=-\frac{1}{\tau}}=0$.

$$
\alpha=\tau\left[1-\sqrt{\left(1-\frac{\lambda}{\tau}\right)^{2} e^{-\theta / \tau}}\right]
$$

Assumptions are complete so that $\alpha$ will not bring in undesired zeros in RHP, for this $\alpha>0$, imply $\tau>\lambda$.

\section{PERFORMANSE ASSESSMENT}

It is famous that an elegant control scheme be supposed to get together the subsequent supplies besides supposed constancy, it should have interruption decrease, Set-point tracking and, Robust constancy and/or healthy presentation. The primary two supplies are usually referred toward since 'Performance' plus the third, 'Robustness' of a control organization $[9,21]$.

\subsection{Performance}

The integral fault be a high-quality calculate used for appraise the set-point plus commotion answer. The subsequent are a little commonly utilize measure based on the integral error used for a step set-point before trouble reply.

$$
\begin{aligned}
& I A E=\int_{0}^{\infty}|e(t)| d t \\
& I S E=\int_{0}^{\infty} e(t)^{2} d t \\
& I T A E=\int_{0}^{\infty} t|e(t)| d t
\end{aligned}
$$

IAE penalizes small errors, ISE large errors and ITAE the errors that persevere for a long time.

\subsection{Robustness Analysis}

Forcefulness is the aptitude of the closed loop scheme to be unfeeling to constituent variation. It is one of the majority helpful properties of feedback. Heftiness is also what makes it likely toward plan reaction scheme based on powerfully basic representation. It required toward include quantitative traditions to articulate how well a feedback scheme perform. Events of appearance and toughness are intimately associated. In closed loop scheme, the sturdiness arrangement be calculate via the compassion purpose (S) which narrate toward trouble elimination possessions whereas the balancing sensitivity function (T) give a gauge of set-point track presentation.

$$
\begin{aligned}
& S \triangleq \frac{1}{1+G_{C} G_{P}} \\
& T \triangleq \frac{G_{C} G_{P}}{1+G_{C} G_{P}}
\end{aligned}
$$

$|S(j \omega)|$ And $|T(j \omega)|$ are the amplitude ratios of $\mathrm{S}$ and $\mathrm{T}$ correspondingly. The utmost values of amplitude ratios give helpful calculate of heftiness and also dish up as manage scheme plan criterion. The most sympathy $M_{S} \triangleq \max _{\omega}|S(j \omega)|$ is the opposite of the straight coldness from Nyquist plot to the critical point. As $M_{S}$ reduce the sturdiness of closed loop system boosts [22-25]. The second strength calculate is $M_{T} \triangleq \max _{\omega}|T(j \omega)|$, referred as booming climax. For an acceptable control system $M_{S}$ be supposed to be in the variety of $1.2-2.0$ and $M_{T}$ should be in the range of $1.0-1.5$ [9]. 


\section{SIMULATION RESULTS}

Two processes are measured for reproduction to reveal efficiency of the future filter cascaded with PID controller for interruption elimination. The progressions measured have been considered and obtainable by other researchers and have unusual $\theta / \tau$ ratio. The closed loop presentation is estimate by means of integral criteria Viz. IAE, ISE, ITAE and the heftiness is estimate by means of the utmost understanding $M_{S}$ for each procedure for unit step load interruption input. The IMC-PID tuning limitations are considered to contain similar strength in conditions of utmost understanding $M_{S}$ to make sure consistent contrast by unreliable $\lambda$. The presentation of the IMC-PID tuning system for the PID controller cascaded with conservative filter recommended by [7] and filter planned by [8, 13], and the enhanced filter arrangement is compared for succinctness.

\subsection{Example 1}

The FOPTD model $G(s)=\frac{1 e^{-10 s}}{100 s+1}[8,10]$, with $\theta / \tau=0.1$ is used for revise. The heftiness with $M_{S}=1.5$ is used for manipulative the controller limitation. The result used for unit step load commotion be exposed into Figure 4 (a) and the Table 1. The sturdiness assessment of the controllers is performed for model disparity by incorporate perturbation of $20 \%$ in the three limitation of FOPTD representation which have the form $G(s)=\frac{1.2 e^{-8 s}}{80 s+1}$. The simulation results of Figure 4(b) and Table 2 read out the sturdiness of the controller cascaded with enhanced filter arrangement.

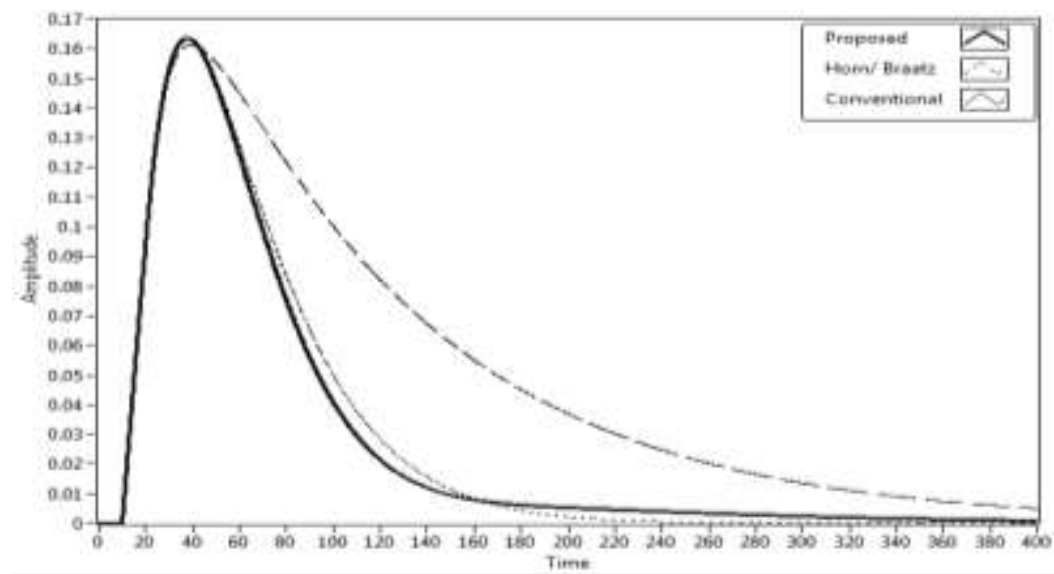

(a)

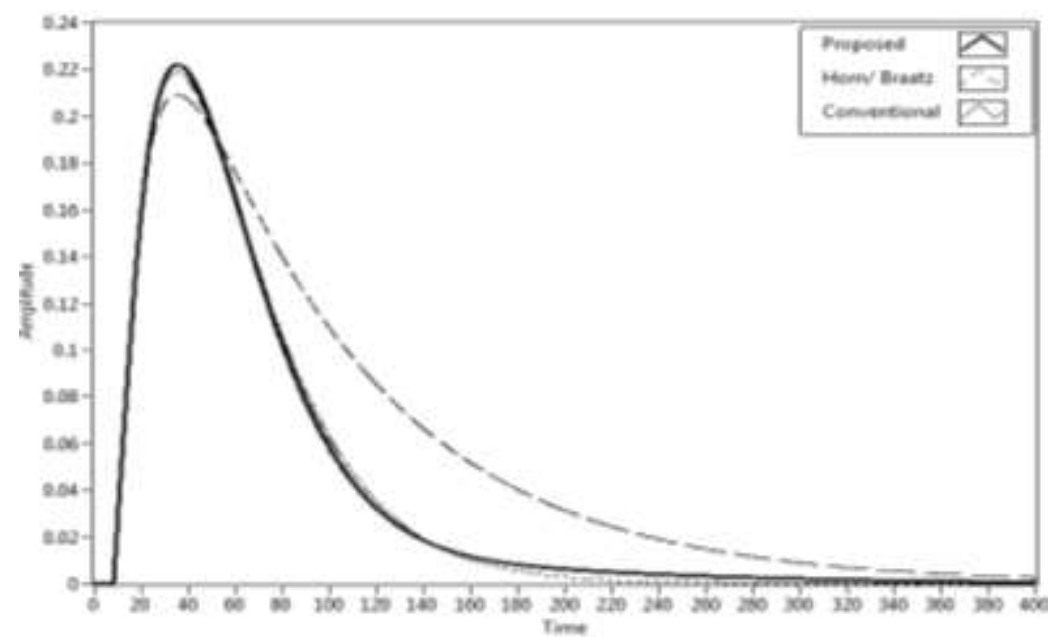

(b)

Figure 4. Responses for step load disturbance input for (a) supposed model (b) $20 \%$ perturbed model 
Table 1. Performance of PID controller for Example 1

\begin{tabular}{ccccccccc}
\hline Tuning Method & $\lambda$ & $\mathrm{K}_{\mathrm{P}}$ & $\mathrm{T}_{\mathrm{i}}$ & $\mathrm{T}_{\mathrm{D}}$ & $\mathrm{M}_{\mathrm{s}}$ & $\mathrm{IAE}$ & $\mathrm{ISE}$ & ITAE \\
\hline Proposed & 30 & 9.195 & 105 & 4.762 & 1.5 & 11.33 & 1.186 & 806.5 \\
Horn et al. & 25.8 & 9.201 & 105 & 4.762 & 1.5 & 11.41 & 1.248 & 726.9 \\
Rivera et al. & 11.35 & 4.918 & 105 & 4.762 & 1.5 & 20.85 & 2.03 & 2391 \\
\hline
\end{tabular}

Table 2. Robustness Analysis of PID controller for Example 1

\begin{tabular}{ccccccccc}
\hline Tuning Method & $\lambda$ & $\mathrm{K}_{\mathrm{P}}$ & $\mathrm{T}_{\mathrm{i}}$ & $\mathrm{T}_{\mathrm{D}}$ & $\mathrm{M}_{\mathrm{s}}$ & $\mathrm{IAE}$ & ISE & ITAE \\
\hline Proposed & 30 & 5.303 & 84 & 3.810 & 1.38 & 15.79 & 2.289 & 1056 \\
Horn et al. & 25.8 & 5.459 & 84 & 3.810 & 1.39 & 15.39 & 2.278 & 928.8 \\
Rivera et al. & 11.35 & 3.618 & 84 & 3.810 & 1.42 & 23.01 & 2.934 & 2247 \\
\hline
\end{tabular}

\subsection{Example 2}

The FOPTD model $G(s)=\frac{0.7717 e^{-56.278 s}}{42.934 s+1}$ [2], with $\theta / \tau>1$ is worn intended for revision. The strength of $M_{S}=1.81$ is used for scheming the manager constraint. The consequence for component stair consignment disorder of nominal replica and $20 \%$ troubled model $G(s)=\frac{0.926 e^{-45.022 s}}{51.521 s+1}$ are shown in Figure 5, Table 3 and Table 4. The consequences point to that controller cascaded with dissimilar forms of filter for process with $\theta / \tau>1$ have the alike trouble rejection competence for supposed replica and manager with better filter provide better response under limit variations.

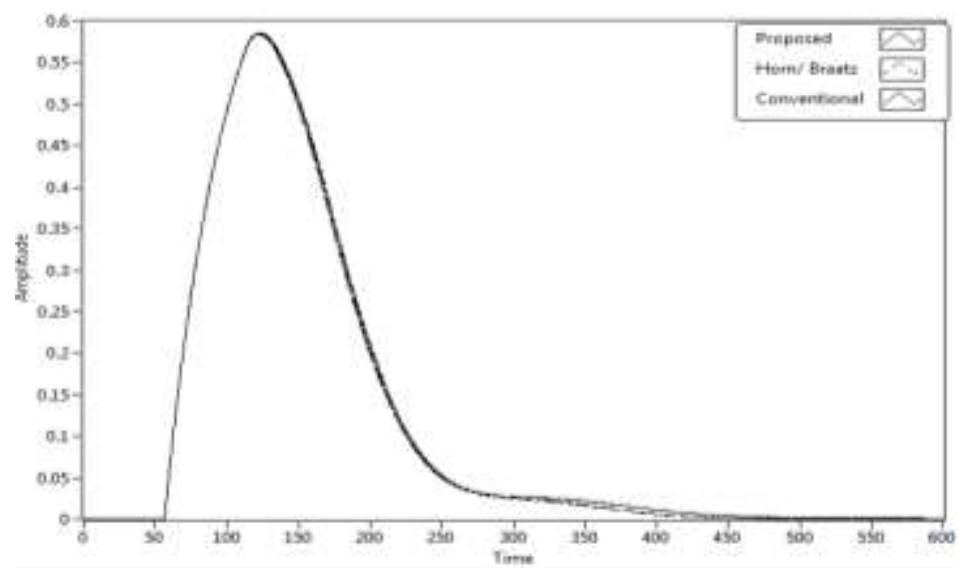

(a)

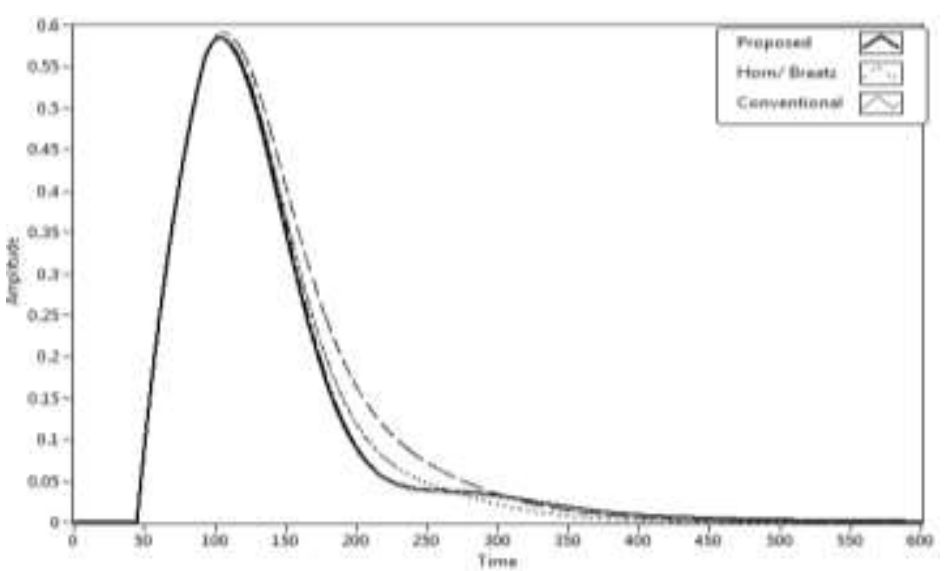

(b)

Figure. 5 Responses for step disturbance input for (a) supposed model (b) $20 \%$ perturbed model 
Table 3. Performance of PID controller for Example 2

\begin{tabular}{cccccccccc}
\hline Tuning Method & $\lambda$ & $\mathrm{K}_{\mathrm{P}}$ & $\mathrm{T}_{\mathrm{i}}$ & $\mathrm{T}_{\mathrm{D}}$ & $\mathrm{M}_{\mathrm{s}}$ & IAE & ISE & ITAE \\
\hline Proposed & 38.95 & 1.041 & 71.073 & 16.998 & 1.81 & 68.31 & 27.52 & 10320 \\
Horn et al. & 36.3 & 1.069 & 71.073 & 16.998 & 1.81 & 66.49 & 27 & 9774 \\
Rivera et al. & 30 & 1.0675 & 71.073 & 16.998 & 1.81 & 66.58 & 26.9 & 9826 \\
\hline
\end{tabular}

Table 4. Robustness Analysis of PID controller for Example 2

\begin{tabular}{ccccccccc}
\hline Tuning Method & $\lambda$ & $\mathrm{K}_{\mathrm{P}}$ & $\mathrm{T}_{\mathrm{i}}$ & $\mathrm{T}_{\mathrm{D}}$ & $\mathrm{M}_{\mathrm{s}}$ & IAE & ISE & ITAE \\
\hline Proposed & 38.95 & 1.196 & 74.032 & 15.666 & 1.90 & 61.86 & 24.17 & 8389 \\
Horn et al. & 36.3 & 1.178 & 74.032 & 15.666 & 1.81 & 62.84 & 25.04 & 8273 \\
Rivera et al. & 30 & 1.066 & 74.032 & 15.666 & 1.71 & 69.46 & 27.46 & 9726 \\
\hline
\end{tabular}

\section{CONCLUSION}

A propose technique for PID controller cascaded with enhanced filter arrangement has been recommended based on IMC fine-tuning method for interruption elimination. The recommended technique provides outstanding presentation for disorder refusal for FOPTD processes. Two processes were measured for reproduction learning which have $\theta / \tau=0.1$ and $\theta / \tau>1$. The simulation has been conducted by tweaking the PID controller cascaded with dissimilar filter arrangement to contain similar sturdiness in the appearance of $M_{S}$ intended for standardized assessment. The toughness examination intended for replica difference has accomplished by integrate $20 \%$ variation in the FOPTD representation restriction. The recommended technique has proved to present outstanding disorder refusal for delay leading progression contrast toward additional technique. It is observed that if $\theta / \tau>1$, the performance is similar to other methods for supposed copy but has high-quality presentation for troubled copy. It is also recommended that in support of processes with $\theta / \tau>1$ the single tuning parameter should be $0.8 \tau<\lambda<\tau$. The suggested method provides brilliant blocked circle presentation which have estimate by means of essential criteria Viz. IAE, ISE, ITAE. The optional technique provides acceptable response for both supposed and troubled models. Obvious cooperation flanked by closed-loop presentation plus toughness toward copy imprecision is attaining by only one alteration limitation $\lambda$.

\section{REFERENCES}

[1] M. Lee, M. Shamsuzzoha, T.N. Luan Vu, "IMC-PID Approach: An Effective way to get an Analytical Design of Robust PID Controller," International Conference on Control, Automation and Systems, pp.2861-2866, Oct 14-17, Seoul, Korea, 2008.

[2] M. Shamsuzzoha, Moonyong Lee, "Analytical design of enhanced PID filter controller for integrating and first order unstable processes with time delay," Chemical Engineering Science, vol. 63, pp.2717-2731, 2008.

[3] Desborough, L. D., Miller, R.M, "Increasing customer value of industrial control performance monitoringHoneywell's experience," Chemical Process Control-VI (Tuscon, Arizona, Jan. 2001), AIChE Symposium Series, vol. 98, no. 326, USA, 2002.

[4] Sahaj Saxena, Yogesh V. Hote, "Advances in Internal Model Control Technique: A Review and Future Prospects", IETE Technical Review, vol. 29, no. 6, pp.461-472, 2012.

[5] M. Morari, E. Zafiriou, "Robust Process Control," Prentice Hall, Englewood Cliffs, NJ, 1989.

[6] Rivera DE, Morari M, Skogestad S, "Internal model control. 4. PID controller design," IndEngChem Process Des Dev., no. 25, pp.252-265, 1986.

[7] Horn IG, Arulandu JR, Christopher JG, VanAntwerp JG, Braatz RD, "Improved filter design in internal model control," IndEngChem Res., 35, pp.3437-3441, 1996.

[8] Seborg DE, Edgar TF, Mellichamp DA, "Process Dynamics and Control,” 2nded. New York, Wiley, 2004.

[9] Lee Y, Park S, Lee M, Brosilow C, "PID controller tuning for desired closed-loop responses for SI/SO systems," AIChE Journal, no. 44, pp.106-115, 1998.

[10] Skogestad S., "Simple analytic rules for model reduction and PID controller tuning," journal process control, no. 13, pp.291-309, 2003.

[11] T. Liu F. Gao, "New insight into internal model control filter design for load disturbance rejection," IET Control Theory Appl., vol. 4, no. 3, pp. 448-460, 2010.

[12] M. Shamsuzzoha and Moonyong Lee, "Design of Advanced PID Controller for Enhanced Disturbance Rejection of Second-Order Processes with Time Delay,” AIChE Journal, vol. 54, no. 6, pp.1526-1536, June 2008.

[13] Adian O' Dwyer, Hand book of PI and PID controller tuning rules, $2^{\text {nd }}$ ed., Imperial College press, London, 2006.

[14] Shamsuzzoha, M., Lee, M, "Analytical design of enhanced PID filter controller for integrating and first order unstable processes with time delay,” Chemical Engineering Science, no. 63, pp. 2717-2731, 2006. 
[15] Sahaj Saxena and Yogesh V. Hote, "Load Frequency Control in Power Systems via Internal Model Control Scheme and Model-Order Reduction," IEEE Transactions On Power Systems, This article has been accepted for inclusion in a future issue of this journal. Content is final as presented, with the exception of pagination.

[16] M. Chidambaram, “Applied Process Control,” Allied Publishers Limited, India, 1998.

[17] Ziegler, J. G., Nichols N. B., "Optimum Settings for Automatic Controllers," Trans. ASME, 64, pp. 759, 1942.

[18] Cohen, G. H., Coon, G. A., "Theoretical Consideration of Retarded Control," Trans. ASME, 75, pp. 827, 1953.

[19] R. Toscano, “A simple robust PI/PID controller design via numerical optimization approach," Journal of Process Control, vol. 15, no. 1, pp. 81-88, February 2005.

[20] Md. Shamsuzzoha, Moonyong Lee, "PID controller design for integrating processes with time delay," Korean Journal of Chemical Engineering, vol. 25, no. 4, pp.637-645, 2008.

[21] P. V. Gopi Krishna Rao, M. V. Subramanyam, K. Satyaprasad, "Design of internal model control-proportional integral derivative controller with improved filter for disturbance rejection," Systems Science \& Control Engineering: An Open Access Journal, vol. 2, no. 1, pp. 583-592, Taylor \& Francis, 2014.

[22] P. V. Gopi Krishna Rao, M. V. Subramanyam, K. Satyaprasad, "Study on PID controller design and performance based on tuning techniques," International Conference on Control, Instrumentation, Communication and Computational Technologies (ICCICCT), pp. 1411-1417, 2014.

[23] Naik, R. Hanuma, DV Ashok Kumar, and P. Sujatha, "Independent controller design for MIMO processes based on extended simplified decoupler and equivalent transfer function," Ain Shams Engineering Journal. 2019.

[24] Moonyong Lee, Masum Jujuly, M., \& Shamsuzzoha, M., "Analytical PI/PID controller design for stable processes," Theories and Applications of Chemical Engineering, vol. 15, no. 1, pp. 126, 2009.

[25] Hanuma Naik, R., DV Ashok Kumar, and P. V. Gopikrishna Rao, "Improved centralised control system for rejection of loop interaction in coupled tank system," Indian Chemical Engineer, pp. 1-20, 2019. 